\title{
Cerebellar ataxia-hypogonadism syndrome
}

INSERM

\section{Source}

INSERM. (1999). Orphanet: an online rare disease and orphan drug data base. Cerebellar ataxia-hypogonadism syndrome. ORPHA:1173

Cerebellar ataxia-hypogonadism syndrome is a very rare autosomal recessive neurodegenerative disorder characterized by the combination of prog ressive cerebellar ataxia with onset from early childhood to the fourth decade, and hypogonadotropic hypogonadism (delayed puberty and lack of secondary sex characteristics). Cerebellar ataxia-hypogonadism syndrome belongs to a clinical continuum of neurodegenerative disorders along with clinically overlapping disorders such as ataxia-hypogonadismchoroidal dystrophy syndrome (see this term). 